Research Article

\title{
A low cost flexible photocatalyst based on silver decorated $\mathrm{Cu}_{2} \mathrm{O}$ nanowires
}

\author{
Kinyas Polat ${ }^{1}$ (D)
}

Received: 31 May 2020 / Accepted: 17 August 2020 / Published online: 23 August 2020

(c) Springer Nature Switzerland AG 2020

\begin{abstract}
In this study a low cost photocatalyst design was introduced based on the silver nanoparticle decorated $\mathrm{Cu}_{2} \mathrm{O}$ nanowires that were grown on flexible copper substrate. Photocatalyst was characterized by using scanning electron microscope, energy dispersive $\mathrm{X}$-ray scattering (EDS), UV-vis diffuse reflectance spectroscopy and X-ray diffractometer. Band gap energy values for $\mathrm{Cu}_{2} \mathrm{O}$ and $\mathrm{Ag}$ decorated $\mathrm{Cu}_{2} \mathrm{O}$ were determined as $2.37 \mathrm{eV}$ and $2.17 \mathrm{eV}$ respectively. Photocatalytic activity was tested against methylene blue (MB) degradation at three different $\mathrm{pH}$ values. Although no noticeable difference was observed, $\mathrm{pH} 5.3$ was faster. Decreasing methylene blue concentration was followed up by UV-vis spectroscopy. Visible light adsorption increased by decorating the $\mathrm{Cu}_{2} \mathrm{O}$ nanowires with silver nanoparticles. Kinetics of degradation was found to be first order with a R-squared value of 0.99 . Nearly total MB was degraded at 300 min. Degradation was verified by high pressure liquid chromatography. Absence of initial MB retention peaks showed a successfully degradation under $100 \mathrm{~W}$ LED light illumination. Flexible copper support under the nanowire arrays presents an advantage of easy removal for the photocatalyst. After the end of the reaction, no photocatalyst residue is left when compared to the powder photocatalyst systems eliminating the heavy filtration processes.
\end{abstract}

\section{Graphic abstract}

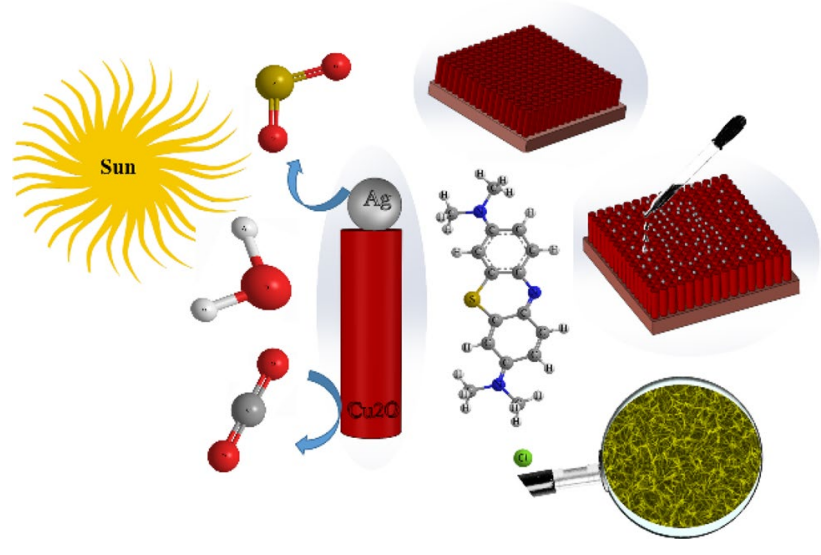

Keywords $\mathrm{Cu}_{2} \mathrm{O}$ nanowires · Silver nanoparticles · Anodizing $\cdot$ Photocatalysis · Methylene blue

Kinyas Polat, kinyas.polat@deu.edu.tr | 'Department of Chemistry, Faculty of Science, Dokuz Eylul University, 35390 Izmir, Turkey. 


\section{Introduction}

Photocatalysts made from the semiconductor compounds have attracted more attention in recent years due to their useful properties in energy harvesting and water treatment applications. In many industries where toxic dyestuffs are intensively used such as textile and paper, considerable amount of polluted water effluents are produced and released into the environment. These dye molecules endanger the aquatic life [1-3]. Semiconductors are useful materials for the eliminating process of these materials in an environmentally friendly way. The mechanism of the degrading molecules by semiconductors rely upon the charge separation during the adsorption of sunlight. Efficient charge separation increases the degradation yield. Copper (I) oxide $\left(\mathrm{Cu}_{2} \mathrm{O}\right)$ is one of those semiconductor materials that can be utilized for this purpose. $\mathrm{Cu}_{2} \mathrm{O}$ has absorption up to $700 \mathrm{~nm}$ in the visible spectrum to benefit from the sun light. $\mathrm{Cu}_{2} \mathrm{O}$ has low photocatalytic performance but its toxicity and cost is low [4-6]. Methods of nanostructure engineering and decoration with noble metals such as silver, gold, platinum are frequently used for enhancing light absorption to improve its activity [7-9]. Silver is the most focused noble metal due to its high electrical and thermal conductivity, chemical resistivity, unprecedented antibacterial properties to produce microelectronics, sensors, catalysts, medical products. Silver is generally used in the form of its binary and ternary composites or hybrids such as $\mathrm{Ag} / \mathrm{TiO}_{2}, \mathrm{Ag} / \mathrm{ZnO}, \mathrm{C}_{3} \mathrm{~N}_{4} / \mathrm{Ag} / \mathrm{ZnO}, \mathrm{Ag} / \mathrm{TiO} /$ graphene [10-12]. Nano engineering efforts that have been tried up to now for enhancing the activity of $\mathrm{Cu}_{2} \mathrm{O}$ yielded the cubes, spheres, octahedral forms $[13,14]$. In recent years, $\mathrm{Cu}_{2} \mathrm{O}$ nanowires have been the focus of scientists for various applications such as solar water separation, sensors [15], catalysts [16], photodetectors [17]. There are three methods for producing $\mathrm{Cu}_{2} \mathrm{O}$ in general. First one is thermal oxidation method in which coper foil is oxidized in the furnace at around $500{ }^{\circ} \mathrm{C}$ [18-21]. The second method is the chemical synthesis in which hydrothermal method is used starting from copper acetate monohydrate at around $180^{\circ} \mathrm{C}[22,23]$. Third one is the electrochemical anodizing method where the anode material is a copper foil and it is anodized to give the nanowires in strong alkali conditions [24]. Among those three methods, electrochemical anodizing method has the least benefited method in the literature.

Herein it was reported construction of an efficient photocatalyst in which nanowires of $\mathrm{Cu}_{2} \mathrm{O}$ decorated with $\mathrm{Ag}$ nanoparticles that were grown on copper foil by electrochemical anodizing method. A new green route for Ag nanoparticles synthesis was also utilized eliminating the extra chemicals usage in wet chemical methods for the first time. Photocatalytic efficiency was tested against methylene blue degradation under visible light and high pressure liquid chromatography (HPLC) was applied for further verification of degradation.

\section{Materials and methods}

\subsection{Reagents}

Copper foil with $0.025 \mathrm{~mm}$ thickness and $99.99 \%$ purity was purchased from Alfa Aesar. $\mathrm{KOH}$ was purchased from Sigma Aldrich. Silver pellets were purchased from Eti Gümüş Turkey and extruded into the $10 \mathrm{~cm}$ long $2 \mathrm{~mm}$ thick rods. Metyhlene blue was purchased from Merck. Acetone and 2-propanole were purchased from Sigma Aldrich.

\subsection{Preparation methods}

\subsection{1 $\mathrm{Cu}_{2} \mathrm{O}$ nanowire synthesis}

$\mathrm{Cu}_{2} \mathrm{O}$ nanowires on copper foil were synthesized by a series of processes as starting from anodizing the copper foil in one-compartment electrolytic cell under dc power supply [25]. For this end, copper foil was cut into the $2 \times 10 \mathrm{~cm}^{2}$ pieces and immersed in a $3 \mathrm{M} \mathrm{KOH}$ solution as the anode of the cell where the cathode side was a stainless steel. Under ambient condition, $4.5 \mathrm{~V}$ and $0.5 \mathrm{~mA}$ was applied to the cell and electrolysis was stopped at $15 \mathrm{~min}$. Before and after the process, copper foil was washed with deionized acetone, 2-propanole and water respectively and allowed to dry in the air. At the end of the process, copper hydroxide, $\mathrm{Cu}(\mathrm{OH})_{2}$ with light blue color was formed on the copper foil which was converted later to the black copper(II)oxide (CuO) with heat treatment on the laboratory heater under air atmosphere at $250^{\circ} \mathrm{C}$ for $30 \mathrm{~s}$. Finally, $\mathrm{Cu}_{2} \mathrm{O}$ nanowires were obtained by the reduction reaction of black $\mathrm{CuO}$ nanowires under nitrogen atmosphere with the aid of hydrogen gas at $500{ }^{\circ} \mathrm{C}$ for $2 \mathrm{~h}$ in quartz furnace. Samples were put into the petri dishes and sealed tightly for further analyses.

\subsubsection{Silver nanoparticle synthesis}

Silver nanoparticles were synthesized for the first time by using an electrochemical cell whose anode and cathode electrodes were made of silver rods. The cell was operated with a power supply ( $12 \mathrm{~V}$ and $1000 \mathrm{~mA})$ for $10 \mathrm{~h}$. Silver bars were cleaned before the process by mechanical scratching to remove the oxidized surfaces and further cleaned by acetone and 2-propanole washing. Yielded 
solution was clear colloidal aqueous silver which was wrapped and saved for further characterizations with aluminum foil to avoid the effects of light.

\subsubsection{Silver decorated $\mathrm{Cu}_{2} \mathrm{O}$ nanowire preparation}

Copper foil having $\mathrm{Cu}_{2} \mathrm{O}$ nanowires was washed thoroughly with 2-propanole and was placed on laboratory heater. Temperature was set to $60^{\circ} \mathrm{C}$. Colloidal silver solution was dropped onto the nanowire surface by using a simple dropper as it completely covered the whole surface area and left to dry for 5 times.

\subsubsection{Characterization}

Detailed characterizations of nanowires, silver decorated nanowires were carried out by Carl Zeiss 300VP scanning electron microscope, Panalytical Empyrean X-ray diffractometer (XRD), Thermo Dionex Ultimate 3000 HPLC system and Perkin Elmer Lambda 950 UV/Vis/NIR Spectrophotometer with reflectance module.

\subsubsection{Photocatalytic activity}

A $100 \mathrm{~mL}$ aqueous solution of methylene blue $\left(2.0 \times 10^{-5}\right.$ $\mathrm{M})$ degraded by a sheet of $2 \times 10 \mathrm{~cm}^{2}$ piece of silver nanoparticle decorated $\mathrm{Cu}_{2} \mathrm{O}$ nanowires on the copper foil under the LED light illumination (100 W $1200 \mathrm{~lm}$ ). Before exposing the light, nanowire sheet immersed in the solution was kept at dark to achieve equilibrium adsorption process for $5 \mathrm{~h}$. Degradation of the methylene blue was then started and tracked by taking samples at fixed intervals. Absorption intensity was measured at $664 \mathrm{~nm}$. Degradation of the methylene blue was verified by HPLC. General process scheme was given in the Fig. 1.

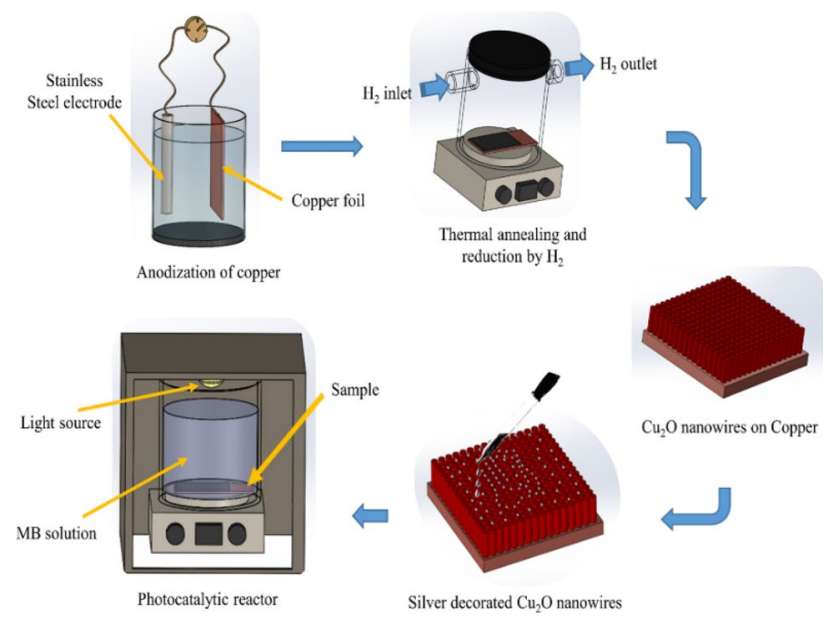

Fig. 1 General process scheme

\section{Results and discussion}

\subsection{Characterization studies}

\subsubsection{XRD}

Crystal phase obtained from anodizing of copper foil was $\mathrm{Cu}(\mathrm{OH})_{2}$. After heat treatment, $\mathrm{CuO}$ was obtained. At the end of reduction reaction in the quartz furnace $\mathrm{Cu}_{2} \mathrm{O}$ was formed and all crystal phases were determined using the $X R D$. Related patterns were given in Fig. 2. From the figure, $\mathrm{Cu}(\mathrm{OH})_{2}$ can be indexed to an orthorhombic phase with $2 \theta$ values at $16.82^{\circ}$ (miller indices: (020)), $23.93^{\circ}$ (miller indices: (021)), $34.16^{\circ}$ (miller indices: (002)) and $39.9^{\circ}$ (miller indices: (130)) (JCPDS file number 13-420). CuO with $2 \theta$ values at $35.6^{\circ}$ (miller indices: $(002) /(-111)$ ) and $38.8^{\circ}$ (miller indices: (111)/(200)) and $\mathrm{Cu}_{2} \mathrm{O}$ with $2 \theta$ values at $43.6^{\circ}$ (miller indices: (200) exhibits monoclinic and cubic structures, respectively (JCPDS file number 45-0937 and 05-0667). In the patterns, the existence of metallic copper is obviously confirmed from the absorptions at about $43.44^{\circ}, 50^{\circ}, 54.79^{\circ}, 74.16^{\circ}, 89.93^{\circ}$ $[26,27]$. Briefly, in going from the $\mathrm{Cu}(\mathrm{OH})_{2}, \mathrm{CuO}$ to $\mathrm{Cu}_{2} \mathrm{O}$, three different crystal phase transitions (orthorhombic, monoclinic and cubic) were encountered. Phase transitions were felt by the morphology changes observed in scanning electron microscope (SEM) images. In all transitions, obtained phases had no amorphous impurities as inferred from the peak sharpness. Base substrate (Copper) dominated the X-ray spectra causing the other peaks to be seen in low intensities.

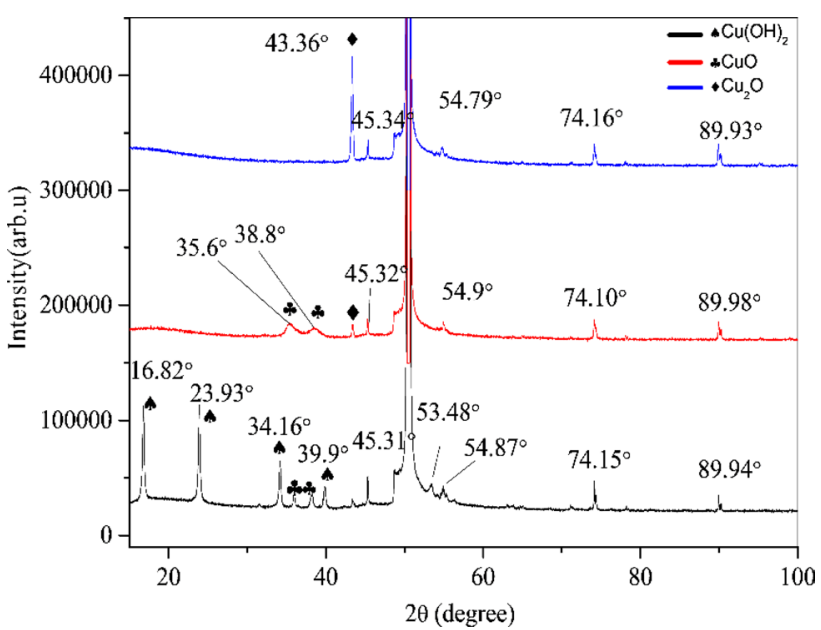

Fig. 2 Characterization of copper oxide samples of different phases by XRD. Indexes were taken from the following patterns: $\mathrm{Cu}_{2} \mathrm{O}$ PDF file number 05-0667, CuO PDF file number 45-0937, $\mathrm{Cu}(\mathrm{OH})_{2}$ file number $13-420$ 


\subsubsection{SEM and EDS}

Figure 3 shows typical SEM images for the formation of $\mathrm{Cu}_{2} \mathrm{O}$ nanowires starting from $\mathrm{Cu}(\mathrm{OH})_{2}$ nanowires. As obvious, $\mathrm{Cu}(\mathrm{OH})_{2}$ nanowires (Fig. $3 \mathrm{a}$, b) have very straight needle like morphology than others and their measured lengths and thickness runs around $10 \mu \mathrm{m}$ and $200 \mathrm{~nm}$. As clearly observed, radius of the needle like nanowires of $\mathrm{Cu}(\mathrm{OH})_{2}$ increases from bottom to the tip. As to the $\mathrm{CuO}$ nanowires in the Fig. 3c, d, it is evidently seen that straightness of the wires was influenced by the heat treatment, oxidation and crystal phase changes, yielding a grass like morphology with no noticeable change in dimensions. A more pronounced morphology change was encountered with $\mathrm{Cu}_{2} \mathrm{O}$ nanowires (Fig. $3 \mathrm{e}, \mathrm{f}$ ) where the grass like morphology of $\mathrm{CuO}$ nanowires transforms into leafless tree like shapes due to the fusion of the bottom parts of nanowires with the effect of heat. SEM images of the silver nanoparticles (Fig. $3 \mathrm{~g}, \mathrm{~h}$ ) reveal that particle sizes change from 20 to $300 \mathrm{~nm}$, the average value of diameter gathers around $200 \mathrm{~nm}$. EDS spectrums of the main structures are introduced in Fig. 4 and clearly verify the corresponding chemical formulas. Peaks of EDS spectrums of all nanowires and silvers nanoparticles were dominated with the bottom base materials (copper metal and silicon wafer) causing some peaks to be seen smaller. Phase transformations of the nanowires were also very distinguishable from the photographs by their colors as they turn from blue, black to the purple.

\subsection{Photocatalytic activity}

Band gap energy value of the photocatalyst was determined by UV-vis diffuse reflectance spectra. In Fig. 5 reflectance spectra was given. From the reflectance spectra, cut off wavelengths were found as $524 \mathrm{~nm}$ and $575 \mathrm{~nm}$ for $\mathrm{Cu}_{2} \mathrm{O}$ and $\mathrm{Ag}$ decorated $\mathrm{Cu}_{2} \mathrm{O}$ respectively. Band gap energy values can be calculated from the cut off wavelengths approximately by using the general equation below;

$E=\frac{h C}{\lambda}$

where $E$ is band gap energy in eV. $C$ is the light velocity, $3.0 \times 10^{8} \mathrm{~m} / \mathrm{s}, h$ is Plank's constant with a value of $6.626 \times 10^{-34} \mathrm{Js}$ and $\lambda$ is cut off wavelength found from the UV-visible reflectance spectrum. Band gap energy values for $\mathrm{Cu}_{2} \mathrm{O}$ and $\mathrm{Ag}$ decorated $\mathrm{Cu}_{2} \mathrm{O}$ were calculated as $2.37 \mathrm{eV}$ and $2.17 \mathrm{eV}$ respectively. As clearly understand that decorating the $\mathrm{Cu}_{2} \mathrm{O}$ with silver nanoparticles enhanced adsorption of visible light by shifting the band gap energy by $20 \mathrm{eV}$ from UV to visible region of the spectrum. Visible light adsorption of the photocatalyst between 400 and $600 \mathrm{~nm}$ is very strong with a nearly $5 \%$ loss. On the other hand, light adsorption value between 600 and $800 \mathrm{~nm}$ is not little to be underestimated, only as much as $50 \%$ light is lost at visible spectrum limit. According to the study in 2011 conducted by Behar Cohen et al. [28], irradiation intensity of warm LED bulbs changes from 0.8 to 1 in going from 480 to $680 \mathrm{~nm}$ and rapidly decreases afterwards. This means that using the LED light is right preference due to the harmony between emission spectrum of LED and reflectance spectra of the photocatalyst between $400 \mathrm{~nm}$ up to $680 \mathrm{~nm}$ where a strong absorption of visible light occurs.

In Fig. 6, first order linear fit plot for the catalytic reaction was given at three different $\mathrm{pH}$ ranges.

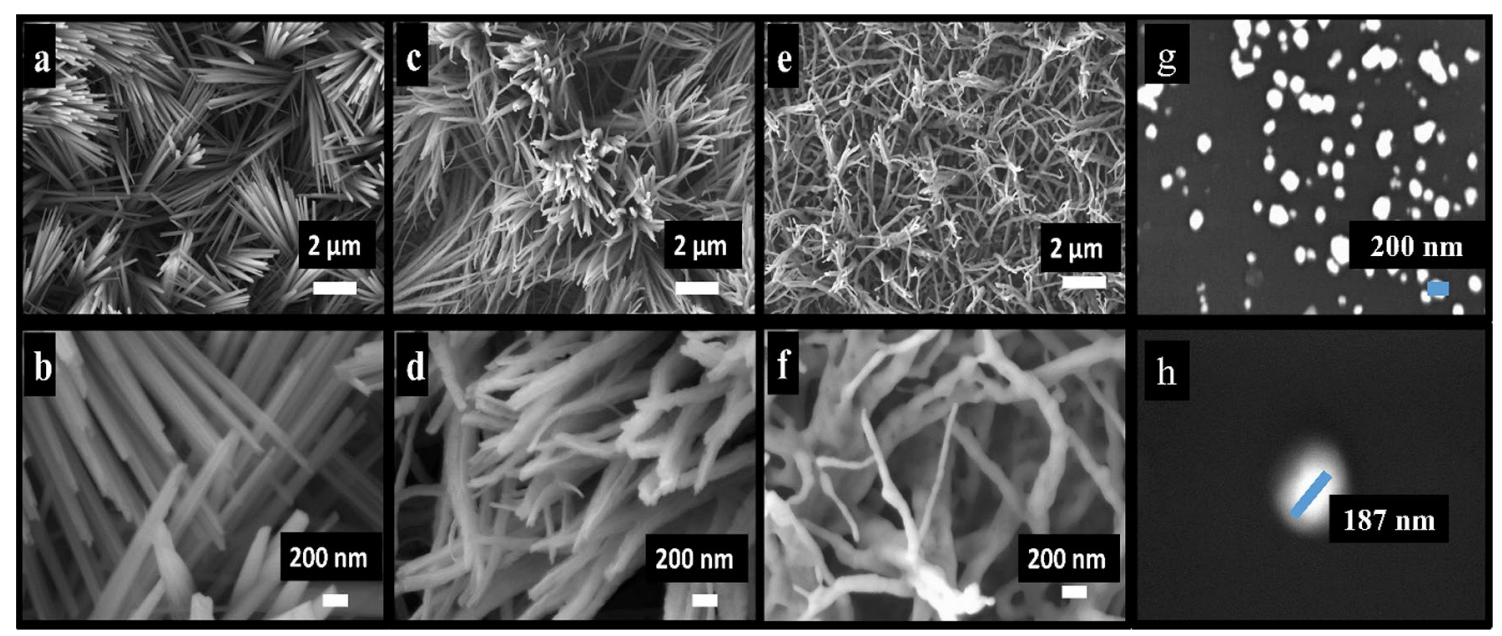

Fig. 3 SEM images showing the gradual formation of $\mathrm{Cu}_{2} \mathrm{O}$ with different magnifications from "a" to "f" and SEM images of Ag nanoparticles on Si substrate; $\mathbf{a}, \mathbf{b} \mathrm{Cu}(\mathrm{OH})_{2}, \mathbf{c}, \mathbf{d ~ C u O}, \mathbf{e}, \mathbf{f} \mathrm{Cu}_{2} \mathrm{O}$ nanowires, $\mathbf{g}, \mathbf{h}$ Ag nanoparticles 

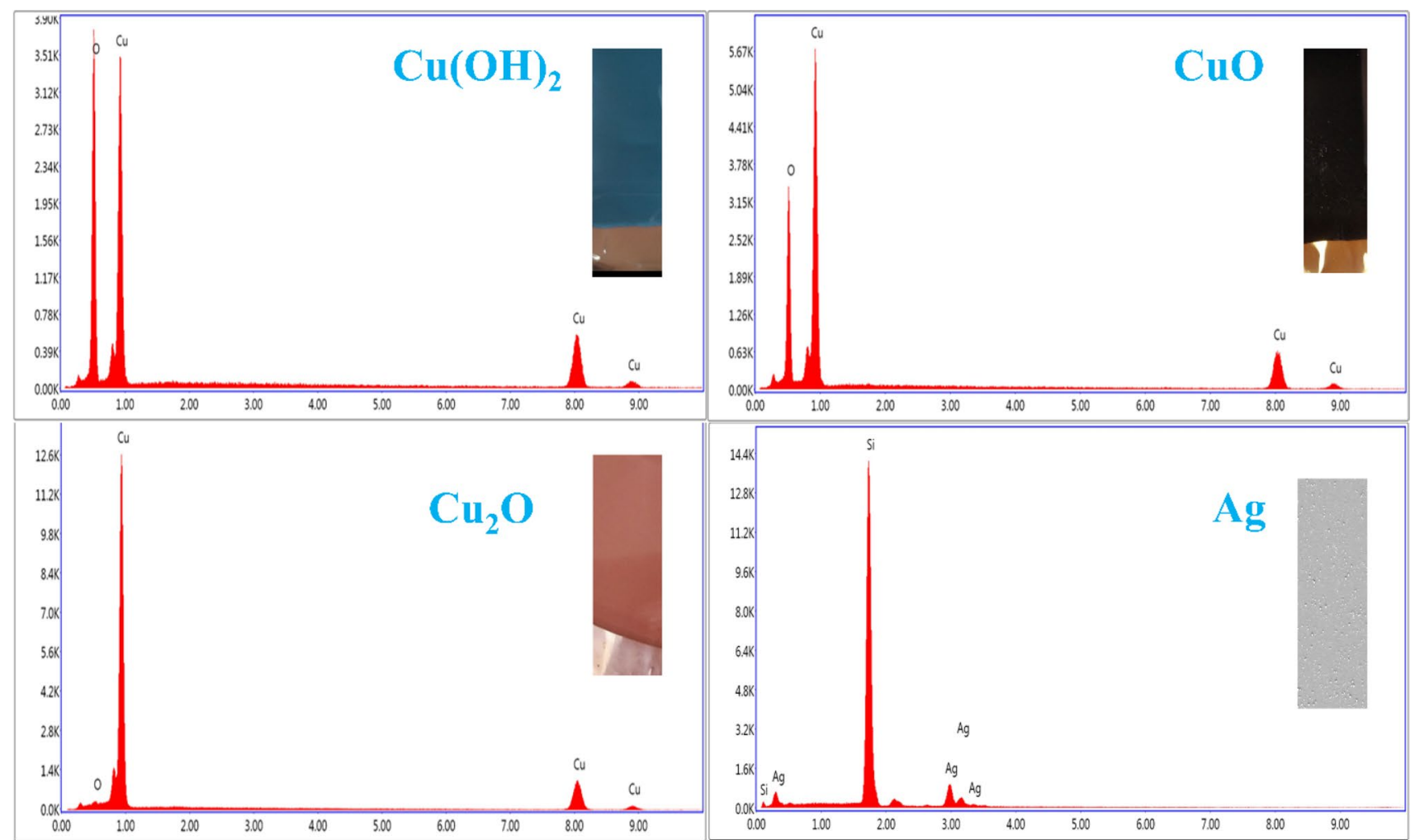

Fig. 4 EDS spectrums of the nanowires on copper foil and their photographs and SEM image of Ag nanoparticles on silicon wafer together with its EDS spectrum

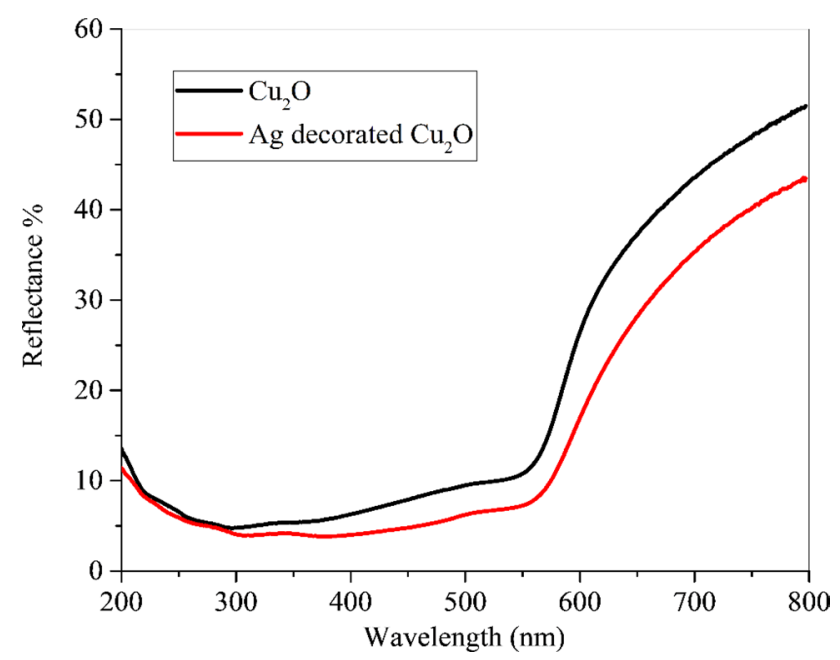

Fig. 5 UV-vis reflectance spectra of $\mathrm{Cu}_{2} \mathrm{O}$ and $\mathrm{Ag}$ decorated $\mathrm{Cu}_{2} \mathrm{O}$

Photocatalytic reaction mechanism perfectly matches the first order kinetic route with the R-squared values of 0.99 . As seen from the Fig. 7 methylene blue concentration is decreased very rapidly and almost nothing left after $300 \mathrm{~min}$. No change was observed in the concentration of $M B$ in the experiment done without

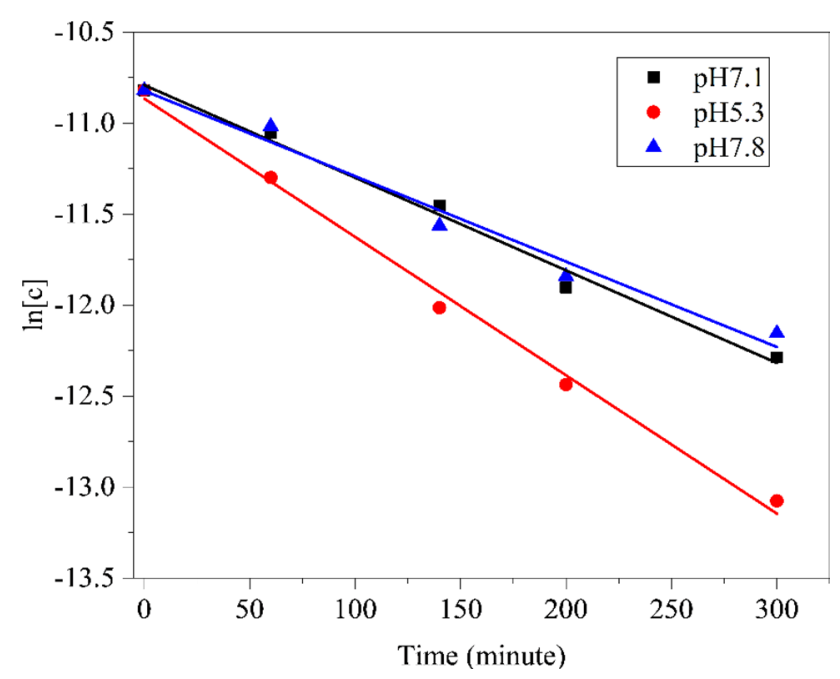

Fig. 6 Linear fit of the photocatalytic reaction to first order

photocatalyst due to the photolysis. Also dark experiment to evaluate the adsorption/desorption equilibrium resulted no observable change in the concentration of MB. In order to identify the effect of silver nanoparticles on the photodegradation efficiency, degradation of $M B$ with pure $\mathrm{Cu}_{2} \mathrm{O}$ was also realized and introduced within 


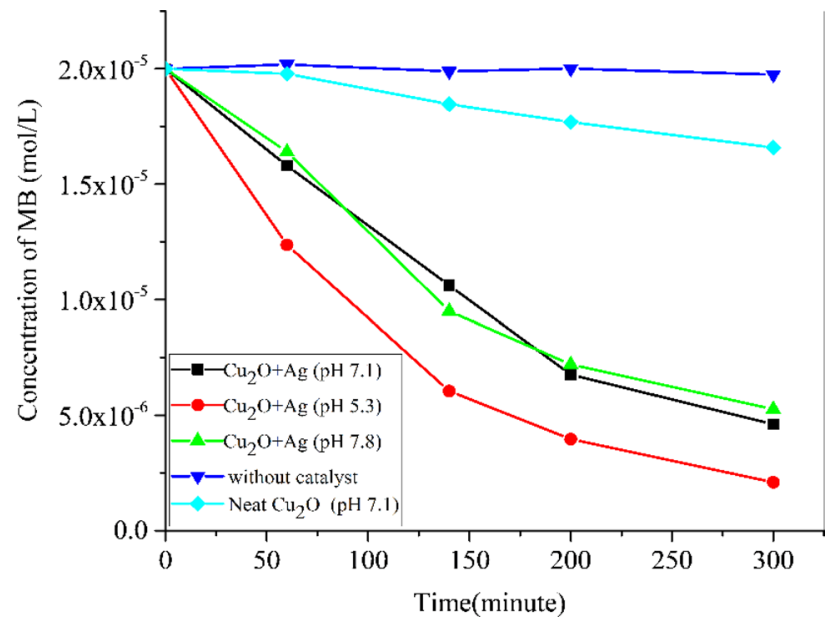

Fig. 7 MB degradation by time

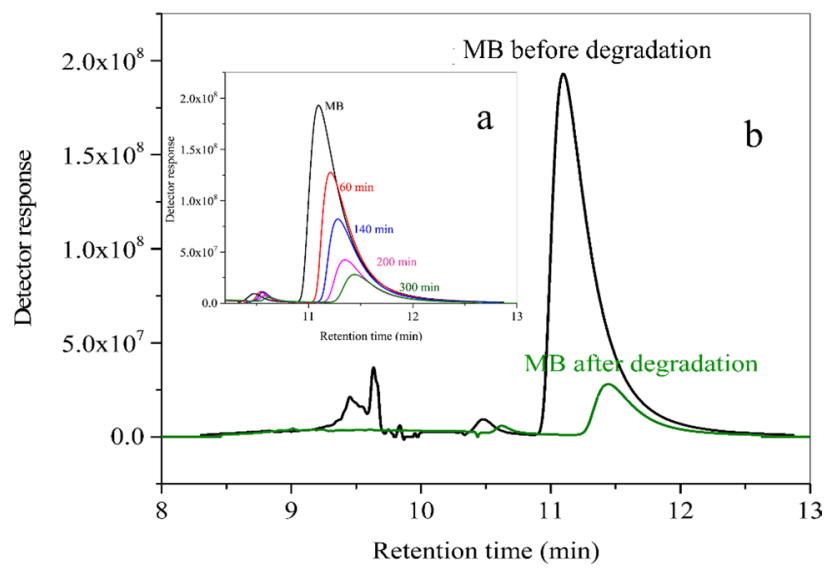

Fig. 8 HPLC chromatograph of photocatalytic MB degaradation

Table 1 R-squared values of linear fitting to evaluate the reaction order

\begin{tabular}{llll}
\hline \multicolumn{2}{l}{ R-squared values } & & \\
\hline & 0. Order & 1. Order & 2. Order \\
\hline $\mathrm{pH} \mathrm{7.8}$ & 0.82 & 0.99 & 0.95 \\
$\mathrm{pH} \mathrm{7.1}$ & 0.96 & 0.99 & 0.96 \\
$\mathrm{pH} \mathrm{5.3}$ & 0.87 & 0.99 & 0.94 \\
\hline
\end{tabular}

the Fig. 8 . Only $12.5 \%$ of the $\mathrm{MB}$ was removed by pure $\mathrm{Cu}_{2} \mathrm{O}$ nanowires while almost all of the $\mathrm{MB}$ was removed by silver decorated $\mathrm{Cu}_{2} \mathrm{O}$ at $300 \mathrm{~min}$. As to the $\mathrm{pH}$ effect on the degradation, only acidic condition made a difference which is not significant but more than the neutral or slightly basic conditions. Light source used in this experiment is only a $100 \mathrm{~W}$ LED bulb. The mechanism of the reaction was also fitted for zeroth and second order

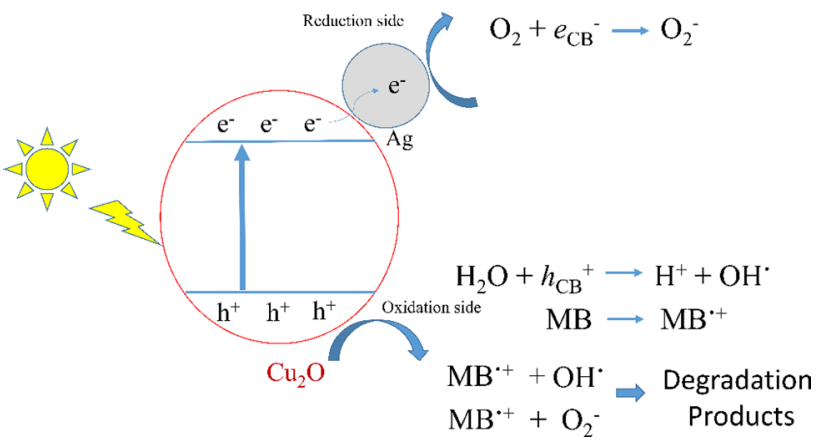

Fig. 9 A schematic representation of photocatalytic MB degradation mechanism

kinetics but the obtained R-squared values (Table 1) was lower than those found for first order kinetics.

\subsection{Photodegradation tracked by HPLC}

HPLC chromatogram for the photocatalytic degradation of MB was given in Fig. 8a, b. Initially, Methylene blue solution gives peak in four different retention times at 9.5, 9.6, 10.5 and $11.1 \mathrm{~min}$ as shown in Fig. 8b. As photodegradation is continued, the peak heights at $11 \mathrm{~min}$ were gradually decreased demonstrating the effective $M B$ degradation under visible light (Fig. 8a). Peaks that belongs to the MB in Fig. $8 \mathrm{~b}$ were almost completely removed and after $300 \mathrm{~min}$ of degradation no peaks at 9.5, 9.6 and $10.5 \mathrm{~min}$ was observed. Additionally, no different peaks were produced during the degradation of $M B$ which may belong to the organic molecules ruptured from MB. This situation clearly proves the successful elimination of $M B$ on the visible active photocatalyst. These results are in good harmony with most of studies where total conversion into the minerals of the dye is proposed. A shematic of degradation mechanism was given in the Fig. 9. According to the mechanism, absorption of visible light by the photocatalyst produces electron and hole pairs. Electrons are immediately grasp by the silver nanoparticles before the recombination and transferred to the oxygen molecules which produce oxygen ions in the reduction side. On the other hand, water molecules react with the hole pairs to produce hydroxyl radicals. MB molecules individually react with the holes to produce exited radical form on the oxidation side. Exited radical forms of methylene blue molecules combine with the oxygen ions or hydroxyl radicals in order to be totally converted to the final degradation products [29]. Easy removal of the photocatalyst which is an advantage for these processes, is shown in Fig. 10. 


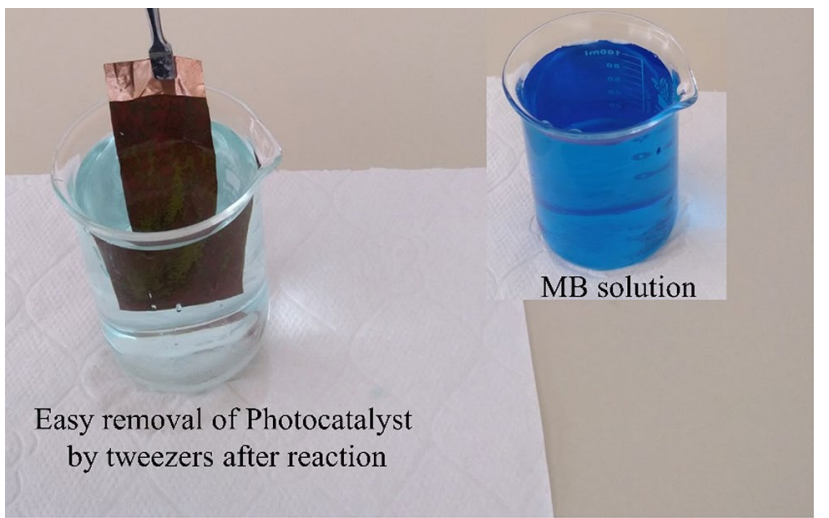

Fig. 10 Photocatalyst removal from the solution

\section{Conclusions}

In this study silver nanoparticles decorated $\mathrm{Cu}_{2} \mathrm{O}$ nanowires were introduced as a visible light active photocatalyst. $\mathrm{Cu}_{2} \mathrm{O}$ nanowires were successfully synthesized by anodizing the copper foil under dc voltage in an alkaline solution by subsequent heat treatments and hydrogen reduction. Silver nanoparticles were produced in an environmentally friendly way using only water and dc electric current. Band gap energy values for $\mathrm{Cu}_{2} \mathrm{O}$ and $\mathrm{Ag}$ decorated $\mathrm{Cu}_{2} \mathrm{O}$ were determined as $2.37 \mathrm{eV}$ and $2.17 \mathrm{eV}$ respectively. Decorating the $\mathrm{Cu}_{2} \mathrm{O}$ with silver nanoparticles enhanced adsorption of visible light by decreasing the band gap energy value by $20 \mathrm{eV}$. Photocatalytic activity of the photocatalyst was evaluated by the performance on MB degradation. Under $100 \mathrm{~W}$ LED illumination $2 \times 10^{-5} \mathrm{M}$ dye solution was mostly degraded within 300 min. Degradation kinetic was found to be in harmony with the first order kinetics with a R-squared values of 0.99 . Three different $\mathrm{pH}$ values were tested. Although no huge difference was observed between the $\mathrm{pH}$ ranges, the most effective one was $\mathrm{pH}$ 5.3. HPLC chromatographs showed a gradual decrease in MB concentration by time. When initial retention peaks of $M B$ and those of 300 min later compared, degradation of MB was clear as inferred from the vanishing original MB peaks. As a result, a new, low cost nano-engineered promising photocatalyst material was developed that can be used for the treatment of dye polluted waste waters. Due the flexible copper support, the material is easily removed from the medium after the end of reaction without leaving any residue. This situation makes an advantage over the powder photocatalysts.

\section{Compliance with ethical standards}

Conflict of interest The author declares that he has no competing interests.

\section{References}

1. Bai Z, Zhang Y (2016) Self-powered UV-visible photodetectors based on $\mathrm{ZnO} / \mathrm{Cu}_{2} \mathrm{O}$ nanowire/electrolyte heterojunctions. J Alloys Compd 675:325-330. https://doi.org/10.1016/j.jallc om.2016.03.051

2. Chen EY, Milleville C, Zide JMO et al (2018) Upconversion of low-energy photons in semiconductor nanostructures for solar energy harvesting. MRS Energy Sustain 5:E16. https://doi. org/10.1557/mre.2018.15

3. Chen J, Wang K, Hartman L, Zhou W (2008) $\mathrm{H}_{2} \mathrm{~S}$ detection by vertically aligned $\mathrm{CuO}$ nanowire array sensors. J Phys Chem C 112:16017-16021. https://doi.org/10.1021/jp805919t

4. Feng $Y$, Zheng $X$ (2010) Plasma-enhanced catalytic CuO nanowires for CO oxidation. Nano Lett 10:4762-4766. https://doi. org/10.1021/nl1034545

5. Gupta D, Meher SR, Illyaskutty N, Alex ZC (2018) Facile synthesis of $\mathrm{Cu}_{2} \mathrm{O}$ and $\mathrm{CuO}$ nanoparticles and study of their structural, optical and electronic properties. J Alloys Compd 743:737-745. https://doi.org/10.1016/j.jallcom.2018.01.181

6. Hilman J, Yost AJ, Tang J et al (2017) Low temperature growth of $\mathrm{CuO}$ nanowires through direct oxidation. Nano-Struct Nano-Objects 11:124-128. https://doi.org/10.1016/j.nanos 0.2017 .08 .004

7. Hongdilokkul P, Chuangchote S, Laosiripojana N, Sagawa T (2017) Conversion of lignin via photocatalysis using synthesized $\mathrm{Ag}-\mathrm{TiO}_{2}$ photocatalysts sintered under different atmospheres. J Sustain Energy Environ 8:101-105

8. Hsu C-L, Chuo Y-C, Hsu L-W et al (2019) UV and visible light induced photocatalytic degradation on $\mathrm{p}-\mathrm{n} \mathrm{Cu}_{2} \mathrm{O} / \mathrm{ZnO}$ nanowires decorated with Au-Pd alloy nanoparticles. Adv Mater Interfaces 6:1801744. https://doi.org/10.1002/admi.201801744

9. Kumar S, Ojha AK, Bhorolua D et al (2019) Facile synthesis of $\mathrm{CuO}$ nanowires and $\mathrm{Cu}_{2} \mathrm{O}$ nanospheres grown on $\mathrm{rGO}$ surface and exploiting its photocatalytic, antibacterial and supercapacitive properties. Phys B Condens Matter 558:74-81. https://doi. org/10.1016/j.physb.2019.01.040

10. Kumar S, Parlett CMA, Isaacs MA et al (2016) Facile synthesis of hierarchical $\mathrm{Cu}_{2} \mathrm{O}$ nanocubes as visible light photocatalysts. Appl Catal B Environ 189:226-232. https://doi.org/10.1016/j. apcatb.2016.02.038

11. Li J, Jin X, Li R et al (2019) Copper oxide nanowires for efficient photoelectrochemical water splitting. Appl Catal B Environ 240:1-8. https://doi.org/10.1016/j.apcatb.2018.08.070

12. Luo J, Steier L, Son $\mathrm{M}-\mathrm{K}$ et al (2016) $\mathrm{Cu}_{2} \mathrm{O}$ nanowire photocathodes for efficient and durable solar water splitting. Nano Lett 16:1848-1857. https://doi.org/10.1021/acs.nanolett.5b04929

13. Mahmoodi V, Bastami TR, Ahmadpour A (2018) Solar energy harvesting by magnetic-semiconductor nanoheterostructure in water treatment technology. Environ Sci Pollut Res 25:82688285. https://doi.org/10.1007/s11356-018-1224-y

14. Pant B, Park M, Kim H-Y, Park S-J (2016) Ag-ZnO photocatalyst anchored on carbon nanofibers: synthesis, characterization, and photocatalytic activities. Synth Met 220:533-537. https:// doi.org/10.1016/j.synthmet.2016.07.027

15. Park Sung-Yeol (2010) Wire-like bundle arrays of copper hydroxide prepared by the electrochemical anodization of $\mathrm{Cu}$ foil. 
Bull Korean Chem Soc 31:2283-2288. https://doi.org/10.5012/ BKCS.2010.31.8.2283

16. Sharma K, Maiti K, Kim NH et al (2018) Green synthesis of glucose-reduced graphene oxide supported $\mathrm{Ag}-\mathrm{Cu}_{2} \mathrm{O}$ nanocomposites for the enhanced visible-light photocatalytic activity. Compos Part B Eng 138:35-44. https://doi.org/10.1016/j.compo sitesb.2017.11.021

17. Tan $Y$, Xue $X$, Peng $Q$ et al (2007) Controllable fabrication and electrical performance of single crystalline $\mathrm{Cu}_{2} \mathrm{O}$ nanowires with high aspect ratios. Nano Lett 7:3723-3728. https://doi. org/10.1021/nl0721259

18. Wang L, Zhang K, Hu Z et al (2014) Porous $\mathrm{CuO}$ nanowires as the anode of rechargeable Na-ion batteries. Nano Res 7:199-208. https://doi.org/10.1007/s12274-013-0387-6

19. Wang $X$, Wu X, Yuan $L$ et al (2017) Ultra-low reflection CuO nanowire array in situ grown on copper sheet. Mater Des 113:297-304. https://doi.org/10.1016/j.matdes.2016.10.029

20. Wu X, Cai J, Li S et al (2016) Au@Cu $\mathrm{O}$ stellated polytope with core-shelled nanostructure for high-performance adsorption and visible-light-driven photodegradation of cationic and anionic dyes. J Colloid Interface Sci 469:138-146. https://doi. org/10.1016/j.jcis.2016.01.064

21. Xu X, Gao Z, Cui Z et al (2016) Synthesis of $\mathrm{Cu}_{2} \mathrm{O}$ octadecahedron/ $/ \mathrm{TiO}_{2}$ quantum dot heterojunctions with high visible light photocatalytic activity and high stability. ACS Appl Mater Interfaces 8:91-101. https://doi.org/10.1021/acsami.5b06536

22. $\mathrm{Xu} \mathrm{Z}, \mathrm{Bi} \mathrm{Z}$, Shen $\mathrm{C}$ (2012) A facile fabrication of $\mathrm{Cu}_{2} \mathrm{O}$ nanowire arrays on Cu substrates. Open Eng. https://doi.org/10.2478/ s13531-012-0007-3

23. Yang C, Dong W, Cui G et al (2017) Highly efficient photocatalytic degradation of methylene blue by P2ABSA-modified $\mathrm{TiO}_{2}$ nanocomposite due to the photosensitization synergetic effect of $\mathrm{TiO}_{2}$ and P2ABSA. RSC Adv 7:23699-23708. https://doi. org/10.1039/C7RA02423A

24. You Q, Liu T, Pang J et al (2019) In situ fabrication of CuO nanowire film for high-sensitive ascorbic acid recognition. Sens Actuators B Chem 296:126617. https://doi.org/10.1016/j. snb.2019.05.094

25. Yu C, Shu Y, Zhou X et al (2018) Multi-branched $\mathrm{Cu}_{2} \mathrm{O}$ nanowires for photocatalytic degradation of methyl orange. Mater Res Express 5:035046. https://doi.org/10.1088/2053-1591/aab516

26. Yu W, Liu J, Yi M et al (2020) Active faceted $\mathrm{Cu}_{2} \mathrm{O}$ hollow nanospheres for unprecedented adsorption and visible-light degradation of pollutants. J Colloid Interface Sci 565:207-217. https ://doi.org/10.1016/j.jcis.2020.01.022

27. Zhang $\mathrm{L}, \mathrm{Ni}$ C, Jiu $\mathrm{H}$ et al (2017) One-pot synthesis of $\mathrm{Ag}^{-\mathrm{TiO}_{2}} /$ reduced graphene oxide nanocomposite for high performance of adsorption and photocatalysis. Ceram Int 43:5450-5456. https://doi.org/10.1016/j.ceramint.2017.01.041

28. Cohen FB, Martinsons C, Viénot F, Zissis G, Salsi AB, Cesarini JP, Enouf O, Garcia M, Picaud S, Attia D (2011) Light-emitting diodes (LED) for domestic lighting: any risks for the eye? Prog Retın Eye Res 30:239-257. https://doi.org/10.1016/j.preteyeres .2011 .04 .002

29. Ammar $\mathrm{H}$, Hinda L, Ksibi M, Elimame E, Chandal G, Herrmann JM (2001) Photocatalytic degradation pathway of Methylene blue in water. Appl Catal B Environ 31:145-157. https://doi. org/10.1016/S0926-3373(00)00276-9

Publisher's Note Springer Nature remains neutral with regard to jurisdictional claims in published maps and institutional affiliations. 